\title{
Gambaran Faktor-Faktor Yang Mempengaruhi Ibu Nifas Menggunakan Jasa Dukun di Wilayah Kerja Puskesmas Bontomarannu Kecamatan Galesong Selatan Kabupaten Takalar 2017
}

\author{
${ }^{1}$ Kurniati A, ${ }^{2}$ Nadyah, ${ }^{3}$ Darmawansyih
}

\begin{abstract}
ABSTRAK
Pendahuluan persalinan adalah Salah satu kasus kesehatan yang masih banyak terjadi di Indonesia dengan pertolongan oleh dukun bayi. Banyak faktor yang memepengaruhi sebagian ibu menggunakan jasa dukun dalam menolong persalinan. Penelitian ini bertujuan untuk mengetahui faktor - faktor yang mempengaruhi ibu nifas menggunakan jasa dukun di Wilayah Kerja Puskesmas Bontomarannu Kec. Galesong Selatan Kab. Takalar. Dengan penelitian deskriptif pada bulan Oktober - November 2017. Populasi dalam penelitian ini semua ibu nifas yang berada di Puskesmas Bontomarannu. Teknik dalam penelitian yang diambil menggunakan purposivesampling sebanyak 36 responden. Analisis data yang dilakukan adalah analisis univariat.
\end{abstract}

Hasil penelitian ini menunjukkan bahwa karakteristik sebagian besar responden adalah sebagai berikut, ibu dengan pendidikan terakhir terbanyak SD yaitu sebanyak 18 responden $(50,0 \%)$, pekerjaan terbanyak ibu rumah tangga yaitu sebanyak 31 responden $(86,1 \%)$. Beberapa alasan ibu menggunakan jasa dukun dalam proses persalinan antara lain : pengetahuan yang rendah sebanyak 30 responden $(83,3 \%)$, tempat praktik dukun lebih dekat dengan tempat tinggal $(69,4 \%)$, melahirkan di rumah sakit butuh banyak biaya (100\%), semua keluarga melahirkan di dukun $(77,8 \%)$, lebih percaya pada dukun dibandingkan petugas kesehatan (77,8\%), sudah sering menggunakan jasa dukun $(61,1 \%)$, banyak jasa dukun di lingkungan sekitar $(69,4 \%)$, dan dukungan dari keluarga untuk menggunakan jasa dukun $(88,9 \%)$.

Kesimpulan berdasarkan hasil penelitian ini, sebaiknya petugas kesehatan terutama bidan bekerja sama dengan instansi kesehatan mengadakan kegiatan penyuluhan agar dapat meningkatkan pengetahuan dan informasi bagi ibu tentang pemilihan penolong persalinan yang tepat.pemantauan dan analisa data pada Ny "N" dengan Usia Kehamilan Preterm di RSUD Syekh Yusuf Gowa Tahun 2018 yakni dari kala I sampai kala IV, tidak ditemukannya komplikasi pada ibu ditandai dengan tanda-tanda vital dalam batas normal, serta bayi mengalami asfiksia ringan disertai BBLR.
*UIN Alauddin Makassar

Kata kunci :

Dukun, Persalinan;

Ibu Nifas

\section{PENDAHULUAN}

Era Sustainable Development Goals (SDGs) atau Tujuan Pembangunan Berkelanjutan telah dimulai saat negara-negara anggota Perserikatan Bangsa-Bangsa (PBB), termasuk Indonesia, menyepakati Outcome Document SDGs pada tanggal 2 Agustus 2015. Dokumen 
ini berisi tentang deklarasi, tujuan, target dan cara pelaksanaan SDGs hingga tahun 2030 . Dokumen ini adalah kerangka kerja pembangunan global baru pengganti Millenium Development Goals (MDGs) yang berakhir tahun 2015 ini, dengan 17 tujuan dan 169 target (Kemenkes, 2015).

Tetapi dengan berakhirnya agenda MDGs pada akhir tahun 2015, Para pemimpin dunia telah menyerukan agenda ambisius baru untuk meningkatkan kehidupan manusia dan melindungi bumi bagi generasi masa depan. Pasca agenda pembangunan 2015, yang dikenal dengan istilah Tujuan Pembangunan Berkelanjutan (SDGs), diharapkan dapat menanggulangi berbagai masalah, termasuk menghapuskan kemiskinan dan kelaparan, memajukan kesehatan dan pendidikan, membangun kota-kota secara berkelanjutan, memerangi perubahan iklim serta melindungi samudera dan hutan (Kemenkes, 2015).

Kematian ibu adalah kematian seorang wanita terjadi saat hamil, bersalin, atau 42 hari setelah persalinan dengan penyebab yang berhubungan langsung atau tidak langsung terhadap persalinan. Organisasi kesehatan tingkat dunia, World Health Organization (WHO) memperkirakan 800 perempuan meninggal setiap harinya akibat komplikasi kehamilan dan proses kelahiran. Sekitar 99\% dari seluruh kematian ibu terjadi di negara berkembang Sekitar $80 \%$ kematian maternal merupakan akibat meningkatnya komplikasi selama kehamilan, persalinan dan setelah persalinan (WHO, 2015).

Menurut laporan WHO yang telah dipublikasikan pada tahun 2014 Angka Kematian Ibu (AKI) di dunia mencapai angka 289.000 jiwa. Di mana terbagi atas beberapa Negara, antara lain Amerika Serikat mencapai 9300 jiwa, Afrika Utara 179.000 jiwa dan Asia Tenggara 16.000 jiwa. Untuk AKI di negara- negara Asia Tenggara diantaranya Indonesia pada tahun 2014 mencapai 214 per 100.000 kelahiran hidup dan tahun 2015 mencapai 207 per 100.000 kelahiran hidup, Filipina 170 per 100.000 kelahiran hidup, Vietnam 160 per 100.000 kelahiran hidup, Thailand 44 per 100.000 kelahiran hidup, Brunei 60 per 100.000 kelahiran hidup, dan Malaysia 39 per 100.000 kelahiran hidup. Memang jika dilihat dari nilai rata-rata AKI di Indonesia masih jauh lebih tinggi daripada negara asia Tenggara lainnya. Hal ini dapat terjadi karena adanya kelompok kehamilan berisiko (WHO, 2015).

Jumlah kematian maternal yang dilaporkan oleh Dinas Kesehatan Kabupaten/Kota di Sulawesi Selatan mengalami penurunan. Jumlah kematian maternal pada tahun 2011 
sebanyak 122 per 100.000 kelahiran hidup, pada tahun 2012 sebanyak 118 per 100.000 kelahiran hidup, dan pada tahun 2013 sebanyak 115 per 100.000 kelahiran hidup dan tahun 2014 yaitu 163 per 100.000 kelahiran hidup dan tahun 2015 yaitu 152 per 100.000 kelahiran hidup. Dilihat dari penyebab Angka Kematian Ibu (AKI) yaitu perdarahan 28\%,biasanya perdarahan pasca persalinan, atonía uteri, komplikasi aborsi tidak aman, eklampsia 24\% dan infeksi 11\% (Kemenkes, 2015). Kematian maternal juga dapat terjadi pada masa nifas. Selain itu proses persalinan dapat terjadi di rumah sakit dengan ditolong oleh petugas kesehatan tetapi juga dapat dilakukan di rumah dan ditolong oleh bidan. Dukun merupakan seorang anggota masyarakat yang pada umumnya adalah seorang wanita yang mendapat kepercayaan serta memiliki keterampilan menolong persalinan secara tradisional.Salah satu kasus kesehatan yang masih banyak terjadi di Indonesia adalah persalinan dengan pertolongan oleh dukun bayi (Saifuddin, AB. 2012). Kenyataannya, hampir semua masyarakat Indonesia baik itu yang tinggal di perdesaan maupun perkotaan lebih senang ditolong oleh dukun. Hal tersebut disebabkan oleh tradisi dan adat istiadat setempat. Tujuan penelitian ini adalah menemukan cara/strategi untuk membangun cohesive network di antara para pemuka setempat, masyarakat, dukun dan bidan dalam melaksanakan pelayanan kesehatan maternal dan perinatal secara bersama-sama.

Hasil penelitian yang dilakukan oleh Musridah Apriliani (2013) di Wilayah Kerja Puskesmas Siko Ternate menunjukkan bahwa dari 138 ibu nifas, sebanyak 52 orang yang sebelumnya menggunakan jasa dukun namun mengalami perdarahan sehingga dirujuk ke puskesmas atau rumah sakit terdekat. Hasil penelitian yang dilakukan oleh Rafida., Dwina Rugaiyah Monayo dari variabel pengetahuan nilai $\mathrm{p}$ 0.000, tingkat nilai $\mathrm{p}$ pendidikan sebesar 0,000, pekerjaan nilai p 0.020 dan keterjangkauan variabel kesehatan nilai fasilitas p 0.040 pengaruh yang signifikan pada pemilihan penolong persalinan di Puskesmas Lokotoy Kabupaten Banggai Utara Banggai Laut. Penolong pesalinan merupakan salah satu bagian dari pelayanan antenatal care .peningkatan pelayanan antenatal, penerimaan gerakan keluarga berencana, melaksanakan persalinan bersih dan aman. Baik di Desa maupun di perkotaan, dukun termasuk tipe pemimpin informal karena pada umumnya mereka memiliki kekuasaan dan wewenang yang disegani oleh masyarakat sekelilingnya. Wewenang yang dimilikinya terutama adalah wewenang kharismatis. Dukun dianggap sebagai orang yang memiliki kekuasaan karismatis. Dengan menjalin kerjasama dengan dukun membuat mereka merasa pekerjaannya terbantu atau lebih ringan. Apalagi para dukun umumnya adalah mereka yang 
sudah sangat dekat dengan masyarakat, sehingga mereka biasanya lebih dahulu tahu jika ada ibu hamil. Selain itu masyarakat juga memang masih membutuhkan kehadiran dukun untuk membantu mereka terutama setelah persalinan selesai untuk membantu membersihkan rumah, memandikan bayinya serta membaca mantra- mantra Data yang diperoleh dari Wilayah Kerja Puskesmas Bontomarannu Kec.Galesong Selatan Kab. Takalar jumlah ibu nifas tahun 2014 sebanyak 288 orang dan pada tahun 2015 jumlah ibu nifas sebanyak 297 orang. Berdasarkan latar belakang masalah, maka peneliti tertarik untuk melakukan penelitian "Gambaran Faktor - Faktor Yang Mempengaruhi Ibu Nifas Menggunakan Jasa Dukun di Wilayah Kerja Puskesmas Bontomarannu Kec.Galesong Selatan Kab.Takalar”.

\section{Rumusan Masalah}

Berdasarkan uraian latar belakang tersebut yang menjadi perumusan masalah dalam penelitian ini adalah bagaimana gambaran faktor-faktor apakah yang mempengaruhi ibu nifas menggunakan jasa dukun di Wilayah Kerja Puskesmas Bontomarannu Kec.Galesong Selatan Kab.Takalar

\section{Tujuan Penelitian}

a. Tujuan Umum

Untuk mengetahui gambaran faktor - faktor yang mempengaruhi ibu nifas menggunakan jasa dukun di Wilayah Kerja Puskesmas Bontomarannu Kec.Galesong Selatan Kab.Takalar.

b. Tujuan Khusus

1) Untuk mengetahui gambaran pengetahuan ibu dengan alasanmenggunakan jasa dukun di Wilayah Kerja Puskesmas Bontomarannu Kec Galesong Selatan Kab. Takalar.

2) Untuk mengetahui gambaran pendidikan ibu dengan alasanmenggunakan jasa dukun di Wilayah Kerja Puskesmas Bontomarannu Kec. Galesong Selatan Kab. Takalar.

3) Untuk mengetahui gambaran pekerjaan ibu dengan alasanmenggunakan jasa dukun di Wilayah Kerja Puskesmas Bontomarannu Kec. Galesong Selatan Kab. Takalar. 


\section{Manfaat Penelitian}

a. Manfaat Aplikatif

1) Dapat memberikan informasi kepada tenaga kesehatan khususnya dukun tentang penggunaan jasa dukun yang merupakan salah satu lingkup upaya promosi kesehatan reproduksi dan berguna bagi masyarakat pada umumnya.

2) Diharapkan dapat memberikan informasi secara objektif tentang gambaran faktor - faktor yang mempengaruhi ibu nifas menggunakan jasa dukun sehingga menjadi pedoman dalam memberikan penyuluhan dalam memberikan pendidikan kesehatan.

b. Manfaat Pengembangan Ilmu Pengetahuan

1) Penelitian ini diharapkan dapat bermanfaat bagi Peneliti terutama untuk menambah wawasan yang berkenaan dengan gambaran faktor - faktor yang mempengaruhi ibu nifas menggunakan jasa dukun, serta menjadi suatu kesempatan yang berharga bagi peneliti untuk dapat mengaplikasikan ilmu-ilmu yang telah diperoleh selama masa.

2) Hasil penelitian ini diharapkan dapat sebagai salah satu bahan bacaan dan acuan bagi peneliti berikutnya.

\section{METODE PENELITIAN}

Penelitian ini menggunakan metode kualitatif. Teknik yang digunakan adalah wawancara mendalam. Informan yang dipilih adalah dukun bayi, bidan, ibu yang melahirkan dengan pertolongan dukun bayi dan ibu yang melahirkan dengan pertolongan bidan. Usahausaha peningkatan pelayanan kesehatan seperti yang tercermin dalam program dukun latih ini memang bukan bertujuan untuk menghilangkan peranan yang dimainkan oleh sistem perawatan kesehatan yang lama dan menggantinya dengan sistem perawatan kesehatan yang baru (Saifuddin, AB. 2012).

\section{HASIL PENELITIAN}

Post partum atau masa nifas adalah masa pulih kembali, mulai dari persalinan sampai alat-alat kandungan kembali seperti sebelum hamil. Lama masa nifas ini yaitu 6 -8 minggu, akan tetapi seluruh alat genital akan kembali dalam waktu 3 bulan. Selain itu masa nifas / purperium adalah masa partus selesai dan berakhir setelah kira-kira 6 minggu, pada masa 
nifas diperlukan perawatan yang baik terutama jika terjadi ruptur saat proses persalinan (Rukiyah, AY. 2010). Faktor yang mempengaruhi ibu nifas dalam menggunakan jasa dukun adalah tingkat pengetahuan ibu karena semakin tinggi tingkat pengetahuan ibu maka akan mempengaruhi seseorang dalam menggunakan jasa dukun. Sedangkan pendidikan yang lebih tinggi akan mudah mendapatkan informasi tentang kesehatan baik dari bidan ataupun dari media elektronik maupun media cetak. Perempuan dengan pendidikan tinggi akan memilih tenaga kesehatan sebagai penolong persalinan selama kehamilan, persalinan, maupun nifasnya. Sedangkan pekerjaan merupakan suatu hal yang kuat dalam pemanfaatan fasilitas kesehatan, perempuan yang menjadi ibu rumah tangga tanpa bekerja diluar rumah secara finansial akan bergantung pada suaminya, sehingga ketika suaminya berpenghasilan sedikit juga akan berdampak terhadap tabungan mereka untuk melahirkan dan menggunakan jasa dukun (Rina, A. 2011). Dalam masa nifas, dukun biasa dipakai untuk melakukan pijatan pada bagian perut, kebanyakan masyarakat mempercayai hal tersebut sebagai salah satu cara agar rahim pulih lebih cepat namun, hal ini belum bisa dibuktikan secara ilmiah. Bedanya dengan tenaga kesehatan para bidan memiliki beberapa tugas dalam mengelola masa nifas yakni, mencegah perdarahan masa nifas oleh karena atonia uteri, mendeteksi dan perawatan penyebab lain perdarahan serta melakukan rujukan bila perdarahan berlanjut. Memberikan konseling pada ibu dan keluarga tentang cara mencegah perdarahan yang disebabkan atonia uteri.

Pemberian ASI awal. Mengajarkan cara mempererat hubungan antara ibu dan bayi baru lahir. Menjaga bayi tetap sehat melalui pencegahan hipotermi. Setelah bidan melakukan pertolongan persalinan, maka bidan harus menjaga ibu dan bayi untuk 2 jam pertama setelah kelahiran atau sampai keadaan ibu dan bayi baru lahir dalam keadaan baik. Memastikan involusi uterus barjalan dengan normal, uterus berkontraksi dengan baik, tinggi fundus uteri di bawah umbilikus, tidak ada perdarahan abnormal. Menilai adanya tanda-tanda demam, infeksi dan perdarahan. Memastikan ibu mendapat istirahat yang cukup. Memastikan ibu mendapat makanan yang bergizi dan cukup cairan. Memastikan ibu menyusui dengan baik dan benar serta tidak ada tanda- tanda kesulitan menyusui. Memberikan konseling tentang perawatan bayi baru lahir (Suherni, 2009).

Pendidikan yang diberikan dalam program dukun ini justru terwujud sebagai pengakuan untuk menyelenggarakan (enforcement) pelayanan kesehatan kepada lembaga 
dukun bayi. Lebih dari itu, dengan pendidikan yang diberikan, dukun bayi dianggap mampu menggantikan kehadiran fasilitas kesehatan yang baik yang dianggap dapat meningkatkan taraf kesehatan penduduk. Kemitraan merupakan salah satu solusi untuk menurunkan masalah kematian ibu dan bayi yang terutama akan menguntungkan daerah-daerah terpencil dimana akses terhadap pelayanan kesehatan sangat terbatas. Masyarakat desa yang masih tradisional memiliki kecenderungan untuk menggunakan jasa"dukun” karena pola berpikir yang masih bersifat irrasional. Masyarakat desa masih mempercayai sesuatu yang berhubungan dengan ghaib, dan seseorang yang menghubungkan mereka dengan sesuatu yang ghaib yaitu seorang "dukun". Adanya tindakan yang ingin dicapai oleh pengguna jasa "dukun" secara irrasional tetapi tujuan yang mereka inginkan bersifat rasional (Saifuddin, AB. 2012)

\section{KESIMPULAN DAN SARAN}

\section{A. KESIMPULAN}

Berdasarkan hasil penelitian tentang gambaran faktor - faktor yang mempengaruhi ibu nifas menggunakan jasa dukun di Wilayah Kerja Puskesmas Bontomarannu Kec. Galesong Selatan Kab. Takalar maka dapat ditarik kesimpulan sebagai berikut :

1. Sebagian besar responden memiliki tingkat pengetahuan yang kurang tentan penggunaan pengunaan jasa dukun dalam proses persalinan yaitu sebanyak 30 responden $(83,3 \%)$.

2. Sebagian besar responden merupakan ibu dengan pendidikan terakhir SD yaitu sebanyak 18 responden $(50,0 \%)$

3. Sebagian besar responden merupakan ibu rumah tangga yaitu sebanyak 31 responden $(86,1 \%)$

4. Sebagian besar responden memiliki alasan menggunakan jasa dukun dalam proses persalinan antara lain : tempat praktik dukun lebi dekar dengan tempat tinggal (69,4\%), melahirkan di rumah sakit butuh banyak biaya (100\%), semua keluarga melahirkan di dukun (77,8\%), lebih percaya pada dukun dibandingkan petugas kesehatan $(77,8 \%)$, sudah sering menggunakan jasa dukun $(61,1 \%)$, banyak jasa dukun di lingkungan sekitar $(69,4 \%)$, dan dukungan dari keluarga untuk menggunakan jasa dukun $(88,9 \%)$.

\section{B. SARAN}

Berdasarkan hasil penelitian yang dilakukan, adapun saran yang dapat diberikan yaitu sebagai berikut: 
1. Bagi Instansi (Rumah Sakit dan Puskesmas)

Hendaknya hasil penelitian ini digunakan sebagai bahan pertimbangan atau informasi bagi pihak layanan kesehatan seperti rumah sakit ataupun puskesmas sehingga mampu melakukan upaya untuk meningkatkan pengetahuan ibu tentang penggunaan jasa dukun dalam proses persalinan yang diharapkan sikap dan tindakan ibu hamil tentang tentang penolong proses persalinan menjadi lebih baik.

2. Bagi Institusi

Diharapkan hasil penelitian ini dapat menjadi bahan bacaan dan sumber informasi untuk mahasiswa kebidanan UIN Alauddin Makassar. selain itu, diharapkan agar peneliti lain dapat melakukan penelitian yang sama dengan variabel yang lebih bervariasi dan mendalam, sehingga dapat diperoleh gambaran secara keseluruhan mengenai faktor faktor yang mempengaruhi ibu memilih dukun sebagai penolong persalinan.

3. Bagi Ibu Hamil dan Nifas

Diharapkan hasil penelitian ini dapat memberikan informasi bagi ibu hamil tentang tentang penggunaan jasa dukun dalam proses persalinan sehingga ibu dapat menentukan penolong persalinan yang tepat.

\section{DAFTAR PUSTAKA}

Ambarwati, 2009. Asuhan Kebidanan Komunitas. Yogyakarta :Nuha Medika.

Amiruddin dan Jakir. 2006. Faktor yang Berhubungan dengan Pemilihan Tenaga Penolong Persalinan oleh Ibu Bersalin di Wilayah Kerja Puskesmas Borong Kompleks Kab. Sinjai Tahun 2006. Buletin Epidemiologi FKM Hasanuddin Makassar.

Andika. 2015. Tindakan Sosial Ibu Hamil Memilih Persalinan keDUkun Beranak di Desa Tanjung Kapur. Naskah Publikasi. Program Studi Ilmu Sosiologi Fakultas Ilmu Sosial Dan Politik Universitas Maritim Raja Ali Haji Tanjungpinang

Anita. 2011. Pengertian Pendidikan.file:///D:/pengerti an-pendidikan-definisi.html. Diakses tanggal 24 Februari 2016, Makassar

Arikunto. 2014. Prosedur Penelitian Suatu Pendekatan Praktik. Jakarta :Rineka Cipta

Azwar, S. 2007. Sikap Manusia Teori dan Pengukurannya, edisi 2. Yogyakarta :Pustaka Pelajar

Bangsu, Thamrin. 2001. Dukun Bayi Sebagai Pilihan Utama Tenaga Penolong Persalinan. Jurnal Penelitian UNIB Volume VII No.2.

Cherawaty, Netty. 2004. Pemilihan Penolong Persalinan (analis akuantitatif) di wilayah Puskesmas Sawah Lebar Kota Bengkulu Tahun 2003. Skripsi FKM-UI.

Departemen Kesehatan RI. 1993. Pedoman Supervisi Dukun Bayi. Direktorat Pembinaan Kesehatan Masyarakat Direktorat Bina Kesehatan Keluarga. http://perpustakaan.depkes.go.id 
Endah, 2013. Pengertian Bidan Menurut WHO,IBI,ICM.http://bidanen dah.blogspot.com/2013/06/pe ngertian-bidan-menurut-ibi- icm-serta.html. Diakses tanggal 17 Februari 2016. Makassar.

Furi, Lili Tiara \& Megatsari, Hario. 2014. Faktor Yang Mempengaruhi Ibu Bersalin Pada Dukun Bayi Dengan Pendekatan Who Di Desa Brongkal Kecamatan Pagelaran Kabupaten Malang. Jurnal Promkes, Vol. 2 No. 1, Juli 2014 : 77-88

Hamid, Abdul Al-Hasimi. 2001. Mendidik Ala Rasulullah. Jakarta: Terjemahan Pustaka Azzam.

Juariah. 2009. Karakteristik ibu bersalin dalam memilih penolong persalinan.http://www.library.upnvj.ac.id/pdf/3keperawata npdf/207312010/bab6.pdf. Diakses tanggal 23 Februari 2016, Makassar

Kemenkes. 2015. Angka Kematian Ibu Menurut Sustainable Development Goals (SDGs)

Kemenkes. 2015. Profil Dinas Kesehatan Provinsi Sulawesi Selatan

Kusumandari, W. 2010. Bidan Sebuah Pendekatan Midwifery Knowledge.Yogyakarta: Nuha Medika

Latifah, N. 2010. Faktor-faktor yang berhubungan dengan pemilihan penolong persalinan. http://eprints. undip.ac.id/23628/1/ Nur_Latifah.pdf. Diakses tanggal 25 Februari 2016, Makassar

Mubarak, Dkk, 2007.Promosi Kesehatan: Sebuah Proses Belajar Mengajar Dalam Pendidikan. Yogyakarta:Graha Ilmu.

Munir, Salham. 2008. Kemitraan bidan dengan dukun bayi.

MusridahApriliani. 2013. Faktor - Faktor Yang Mempengaruhi Ibu Nifas Menggunakan Jasa Dukundi Wilayah Kerja Puskesmas Siko Ternate

Manuaba, IBG. 2010. Gawat Darurat Obstetri-Ginekologi dan Obstetri Ginekologi Sosial Untuk Pendidikan Bidan. Jakarta: EGC

Mansjoer, A. 2009. Kapita Selekta Kedokteran. Jakarta : Aesculapius

Meilani, N. dkk. 2009. Kebidanan Komunitas. Yogyakarta :Fitramaya

Notoatmodjo S.2007. Promosi Kesehatan dan Ilmu Perilaku. Jakarta: Rineka Cipta.

Notoatmodjo, S.2010. Ilmu Perilaku Kesehatan.Jakarta :Rineka Cipta.

Notoatmodjo. S. 2014. Metode Penelitian Kesehatan. Jakarta : EGC

Nuraeni, Sitti dan Purnawati, Dewi. Perilaku Pertolongan Persalinan Oleh Dukun Bayi Di Kabupaten Karawang 2011. Prosiding Seminar Nasional Kesehatan Jurusan Kesehatan Masyarakat FKIK UNSOED Purwokerto, 31 Maret 2012

Nurhasni. 2010.Faktor-faktor yang Mempengaruhi Pemilihan Penolong Persalinan di Wilayah kerja Puskesmas Cijeruk Kecamatan Cijeruk Kabupaten Bogor. Skripsi. FKM-UI Depok.

Prawirohardjo, S. 2010. Ilmu Kebidanan. Jakarta : YBP-SP

Rina, A. 2011. Penggunaan Jasa Dukun Dalam Masa Nifas

Rafida. 2013.Factors Affecting The Interests Of Pregnant Women Prefer Birth Support Delivery In Work Area Health District Lokotoy Banggai Banggai North Sea

Rukiyah, AY. 2010. Asuhan Kebidanan IV Patologi Jakarta : TIM

Retna, Eni. 2011. Asuhan Kebidanan Masa Nifas. Yogyakarta :Fitramaya

Saifuddin, AB. 2009. Ilmu Kebidanan. Jakarta : Yayasan Bina Pustaka Sarwono Praworohardjo

Saifuddin. 2012, Buku Praktis Pelayanan Maternal Dan Neonatal. Jakarta: EGC

Siswati, dkk. 2011. Perspektif Pertolongan Persalinan Oleh Dukun Bayi Di Desa Bumi jawa Kecamatan Bumi jawa Kabupaten Tegal Tahun 2009. Pena Jurnal Ilmu 
Pengetahuan dan TeknologiVol 21. No 1 (2011) : Pena Jurnal Ilmu Pengetahuan danTeknologi, September 2011

Soemanto, Wasty, \& Soetopo, Hendiat, 2010. Dasar dan Teori Pendidikan Dunia tantangan bagi para Pemimipin Pendidikan, Surabaya.Usaha Nasional

Soepardan, S. 2010. Konsep Kebidanan. Bandung : EGC

Suherni. 2009. Perawatan Masa Nifas. Jakarta : EGC

Sujatmoko. 2015. Gambaran Faktor- Faktor Ibu Bersalin Dalam Memilih Pertolongan Persalinan Dengan Bantuan Dukun Bayi di UPTD Puskesmas Wonosegoro Boyolali fakultas Ilmu Kesehatan Universitas Muhammadiyah Surakarta

Sukmadinata, N. 2007. Landasan Psikologi Proses Pendidikan. Bandung: Remaja Rosdakarya Offset.

Suseno. 2010. Faktor-faktor yang berhubungan dengan pemilihan penolong persalinan. http://eprints. undip.ac.id/23628/1/ Nur_Latifah.pdf. Diakses tanggal 25 Februari 2016, Makassar

Sujiyatini, dkk. 2011. Asuhan Kebidanan II (Persalinan). Yogyakarta :Rohima Press

Syafruddin. 2009. Kebidanan Komunitas. EGC. Jakarta

Trimaryanti, Eny.2016. Faktor- Faktor Yang Berhubungan Dengan Memilih Dukun Bayi Sebagai Penolong Persalinan (Studi Ibu Primipara Di Wilayah Kerja Puskesmas Kakap Dan Puskesmas Sui. Rengas). Skripsi. Program Studi Kesehatan Masyarakat Fakultas Ilmu Kesehatan Universitas Muhammadiyah Pontianak

Vivi, NLD. 2011. Asuhan Kebidanan Pada Ibu Nifas. Jakarta :SalembaMedika

WHO, 2015. Angka Kematian Ibu, (online). Diakses tanggal 15 Februari 2016, Makassar

Wahyudi, A. 2010. Faktor-faktor yang mempengaruhi ibu dalam memilih penolong persalinan. http://jurnal. pdii.lipi.go.id/admin/j urnal/22101020_2085-028X.pdf. Diakses tanggal 26 Februari 2016, Makassar

Widyatun, Diah. 2012. Ambulance Desa Di Komunitas. http://jurnalbidandiah.blogsp ot.com/2012/06/ambulance- desadikomunitas.html

Wulansari, Triani. 2010. Analisis Spasial Pemilihan Tempat Pertolongan Persalinan. Jurnal Ilmiah. $\quad$ http://ejournal.litbang.depkes. go.id/index.php/kespro/article /download/1387/694 